\title{
Simulating Infiltration Tests in Fractured Basalt at the Box Canyon Site, Idaho.
}

\author{
André J.A. Unger ${ }^{*}, \mathrm{a}$, Boris Faybishenko ${ }^{\mathrm{a}}$, Gudmundur S. Bodvarsson ${ }^{\mathrm{a}}$, and Ardyth M. Simmons ${ }^{\mathrm{b}}$ \\ ${ }^{a}$ Earth Sciences Division, Lawrence Berkeley National Laboratory, Berkeley, California, USA \\ 94720 \\ ${ }^{b}$ Earth and Environmental Sciences Division, Los Alamos National Laboratory, Los Alamos, \\ New Mexico, USA 87545 \\ *Corresponding author (AJAUnger@1bl.gov) Phone: (510) 495-2823 Fax: (510) 486-5686
}




\begin{abstract}
The results of a series of ponded infiltration tests in variably saturated fractured basalt at Box Canyon, Idaho, were used to build confidence in conceptual and numerical modeling approaches used to simulate infiltration in fractured rock. Specifically, we constructed a dual-permeability model using TOUGH2 to represent both the matrix and fracture continua of the upper basalt flow at the Box Canyon site. A consistent set of hydrogeological parameters was obtained by calibrating the model to infiltration front arrival times in the fracture continuum as inferred from bromide samples collected from fracture/borehole intersections observed during the infiltrating tests. These parameters included the permeability of the fracture and matrix continua, the interfacial area between the fracture and matrix continua, and the porosity of the fracture continuum. To calibrate the model, we multiplied the fracture-matrix interfacial area by a factor between 0.1 and 0.01 to reduce imbibition of water from the fracture continuum into the matrix continuum during the infiltration tests. Furthermore, the porosity of the fracture continuum, as calculated using the fracture aperture inferred from pneumatic-test permeabilities, was increased by a factor of 50 yielding porosity values for the upper basalt flow in the range of 0.01 to 0.02 . The fracture-continuum porosity was a highly sensitive parameter controlling the arrival times of the simulated infiltration fronts. Porosity values are consistent with those determined during the Large-Scale Aquifer Pumping and Infiltration Test at the Idaho National Engineering and Environmental Laboratory.
\end{abstract}




\section{Introduction}

The Idaho National Engineering and Environmental Laboratory (INEEL) contains approximately one-third of the Department of Energy (DOE) total inventory of plutonium-contaminated waste. This waste resides in the $144,100 \mathrm{~m}^{2}$ Subsurface Disposal Area (SDA) within the Radioactive Waste Management Complex (RWMC) and was placed in shallow pits, soil vaults and trenches in sediments overlying variably saturated basalts over a 32-year period. Net infiltration is the principal mechanism for transporting this radioactive waste from the surface down to the water table where it may potentially contaminate potable water supplies.

The motivation of this work is to report on our modeling efforts to simulate infiltration in the variably saturated basalt at the Box Canyon Site, Idaho, located approximately $16 \mathrm{~km}$ from the RWMC of the INEEL where the Large-Scale Aquifer Pumping and Infiltration Test (LPIT) was conducted. Dunnivant et al. (1998) as well as Magnuson (1995) report on experimental and numerical modeling results of the $26,300 \mathrm{~m}^{2}$ LPIT to identify mechanisms controlling infiltration in fractured basalts. Following the LPIT, a series of ponded infiltration tests were conducted at the Box Canyon site to mimic episodic surface-flooding events that occur during large rainstorms or snowmelt events. Details concerning these tests can be found in Faybishenko et al. (1998a, 1999). The ponded infiltration tests represent extreme infiltration conditions for transporting radioactive waste stored at the surface at the INEEL to the water table. The objective of this work is to examine the applicability of a conceptual and numerical model, which is based upon the continuum approach for representing the basalt fracture-matrix system, to simulate infiltration in fractured rock. In particular, the model will be used to simulate the Box Canyon infiltration test data. Pruess et al. (1999) describe alternative concepts and approaches for modeling flow and transport in unsaturated zones of fractured rocks. 
The Box Canyon site is located in the Eastern Snake River Plain near the INEEL (see Figure 1) and is adjacent to the Big Lost River. The Snake River Plain is primarily composed of fractured Quaternary basalt flows interbedded with sedimentary deposits. Sedimentary interbeds may separate basalt flow units that were formed at disparate times, and their thickness may range from a few centimeters to as much as 15 meters. Basalt flow units are comprised of a number of basalt flows arising from the same eruption event. Individual basalt flows are from $3 \mathrm{~m}$ to $12 \mathrm{~m}$ thick and exhibit an extreme elongation in one direction, giving them a finger or lenticular structure with a width ranging from $20 \mathrm{~m}$ to $60 \mathrm{~m}$. The total basalt thickness in the Snake River Plain may exceed three kilometers (Welhan and Reed, 1997; Knutson et al., 1993). The Box Canyon site is located on a basalt flow, approximately $10 \mathrm{~m}$ to $12 \mathrm{~m}$ thick with a nearby cliff face exposure at the Big Lost River. Additional basalt flows underlie the upper basalt flow directly beneath the experimental site.

The Box Canyon infiltration tests were conducted in the same variably saturated fractured basalt as the LPIT. Dunnivant et al. (1999) present an overview of the LPIT and indicate two observations which have significant implications for the analysis in this work. First, although vertical water flow in the vadose zone during the LPIT was confined within a cylinder directly beneath the infiltration basin, wetting did not progress as a front uniformly distributed across this area. Neutron logs indicated that preferential flow paths exist within fractures and rubble zones given by intermittent wetting zones as these features intersect the borehole with depth. Second, breakthrough curves of a conservative ${ }^{75} \mathrm{Se}$ tracer were highly erratic and indicated that a variety of different flow-paths ranging from individual fractures to interconnecting flow paths were present beneath the LPIT infiltration basin. Both of these observations apply to data collected during the Box Canyon infiltration tests. Despite the discrete nature of these flowpaths, we use a simplified fracture-matrix continuum approach to modeling flow of infiltrating water given that it is impossible to fully characterize these flowpaths with the limited data available. 
This analysis of the Box Canyon infiltration experiments involved calibrating hydrogeological parameters in a dual-permeability model of the Box Canyon site to match the arrival times of the infiltration front at various monitoring points. The dual permeability approach had been used extensively to simulate variable saturated flow in fractured rocks (Barenblatt et al., 1960; Pruess and Narasimhan, 1985; Dean and Lo, 1988; Bandurraga and Bodvarsson, 1999; McLaren et al, 2000). Specifically, application of dual-permeability models to simulate fracture-matrix flow of infiltrating water in the variably saturated tuffs at Yucca Mountain has evolved through various conceptual stages. In general, they involve reducing the interfacial area between the fracture and matrix continua, and hence the degree to which they interact. Furthermore, the matrix continuum may be represented as a single or multiple interconnected nodes to spatially resolve the imbibition of water from the fracture continuum. Bandurraga and Bodvarsson (1999) describe the initial application of a dual-permeability model to Yucca Mountain where the matrix continuum is represented using a single node and the fracture-matrix interfacial area is multiplied by a constant factor ranging from 0.0005 to 0.05 . Doughty (1999) performed a sensitivity analysis using various procedures to scale the interfacial area between the fracture and matrix continua depending on the constant factor approach, the relative permeability of the liquid in the fracture continuum, and finally the saturation of the infiltrating liquid in the fracture continuum. Alternative representations of the matrix continuum were also included. Finally, Liu et al. (1998) developed an "active fracture" representation where a single parameter is used to estimate the fraction of fractures which actively conduct water, the spacing between these fractures, and the fracture-matrix interfacial-area reduction factor. All of this work has focussed on calibrating the Yucca Mountain model to measured steady-state water-saturation and capillary-pressure profiles resulting from infiltration from long-term averaged precipitation over the site. We applied the dual-permeability approach at Box Canyon to simulate the transient migration of water from short-term infiltration events. Furthermore, extensive field work at the Box Canyon site focused 
on delineating fractures that actively conducted the infiltrating water. Given the significant decrease in scale from the Yucca Mountain to Box Canyon model, the transient nature of the infiltration events and the subsequent characterization of active water-conducting fractures, we adopted the initial implementation of the dual-permeability modeling approach as performed by Bandurraga and Bodvarsson (1999).

The structure of this paper involves developing an initial geological conceptual model of the fractured basalt at Box Canyon. Next, we describe the development of a numerical representation of the conceptual geological model. Pneumatic test data is then used to calibrate fracturecontinuum permeability in the numerical model. Finally, infiltration front arrival times inferred from bromide data are used to calibrate fracture-continuum porosity, fracture-matrix continua interfacial area and matrix-continuum permeability.

\section{Geological Model Conceptualization}

Conceptualization of the geological model for the Box Canyon site follows directly from Faybishenko et al. (1999) and is used here to address issues related to flow of infiltrating water in the basalt hydrogeological system. The site consists of layered basalt flows containing horizontal and vertical columnar fractures resulting from cooling of the basalt. Field data at the Box Canyon site was gathered from pneumatic and infiltration tests almost entirely within the upper basalt flow. The elevation of the ground surface at the site is shown on Figure 2a, along with the surface location of all instrumented vertical and slanted boreholes. The bottom of the upper basalt is identified by the presence of a rubble zone observed in core samples and open borehole measurements (Faybishenko et al., 1998b). The top elevation of this rubble zone is shown in Figure $2 \mathrm{~b}$. The surfaces shown in Figures $2 \mathrm{a}$ and $2 \mathrm{~b}$ result in an average thickness of the upper 
basalt flow of approximately $12 \mathrm{~m}$. The box outline indicates the perimeter of the infiltration pond used to contain the ponded water at the ground surface.

Grossenbacher and Faybishenko (1995) mapped horizontal and vertical columnar basalt fractures along an outcrop near the Box Canyon site. They observed that the vertical fracture spacing increased from ground surface to a dimensionless depth of 0.6 . The dimensionless depth is defined as the depth from the ground surface divided by the thickness of the upper basalt flow. Vertical fracture spacing then decreased from the dimensionless depth of 0.6 to the bottom of the basalt flow. Basalt columns were formed as the basalt cooled and subsequently shrank, inducing the vertical fractures to relieve tensional stresses. The upper basalt cooled more rapidly from the ground surface downward than from the bottom upward because of the larger temperature gradients near the surface causing the fracture spacing to be smaller at the ground surface than at the bottom of the basalt. Columnar fractures originating from the top and bottom of the basalt reached an identical spacing where the two cooling fronts met at the dimensionless depth of 0.6. To construct the conceptual geological model, the vertical fracture spacing as a function of dimensionless depth was used to subdivide the upper basalt flow into five zones extending from the ground surface to the bottom, in the following intervals: $0-0.2,0.2-0.4,0.4-0.6,0.6-0.8$ and 0.8-1.0. The horizontal and vertical fracture spacing, $D_{H}$ and $D_{V}$, for each zone are provided in Table 1. Figure $2 \mathrm{c}$ shows a cross-section through the upper basalt flow along the transect indicated on Figure 2a. The cross-section shows the conceptual fracture pattern used to establish the zonal structure. The orientation of the cross-section is taken along the direction of the S-series of wells (S-1 to S-4) which were primarily used for pneumatic testing to infer fracture permeabilities.

The focus of the conceptual geological model is to address issues related to flow of infiltrating water in the basalt hydrogeological system. With this in mind, we examined hydrogeological data 
collected by Faybishenko et al. (1998a, 1999) for the 96-1 and 97-1 to 97-4 infiltration tests to determine whether fractures that actively conducted water could be observed as they intersected the boreholes shown on Figure 2a. These features were inferred from bromide samples, lysimeter, tensiometer, time domain reflectometry (TDR) probe and electrical resistivity (ER) probe data collected during the 96-1 infiltration test as well as additional ER probe and bromide sample data collected during the 97-1 to 97-4 infiltration tests. The layout of these observation points is shown on Figure 3. Details concerning the depth along the borehole where the water conducting features was observed as well as the instrumentation used to detect the feature are provided in Unger et al. (2002) From the perspective of constructing this conceptual model, it is only important to note that a feature that actively conducted water was detected while the actual instrumentation used to detect the feature is unimportant.

\section{Numerical Model Conceptualization}

The conceptual geological model was used to develop a numerical model to simulate the physics of water- and gas-phase advection through the fractured basalt at Box Canyon. The numerical modeling effort was conducted using TOUGH2 (Pruess, 1991) with the EOS3 module, which involves both mobile water and gas phases. This was necessary because calibration of the model involved analysis of both pneumatic and infiltration test data. Flow of water and gas though the fractures and matrix of the basalt rock was simulated using the dual-permeability approach which involves using two separate nodes representing both fracture and matrix continua. These nodes occupy the same geometric volume within the grid and are interconnected at each geometric volume within the grid where they overlap. Furthermore, the fracture-continuum nodes are connected to adjacent fracture-continuum nodes, while the matrix-continuum nodes are connected to adjacent matrix-continuum nodes. 
A three-dimensional (3-D) model was constructed using the dual-continuum modeling approach for the upper basalt flow (as well as the rubble zone and a portion of the lower basalt). The lateral extent of the model is given by Figure 2a. The bottom of the model is at a uniform elevation of $1579 \mathrm{~m}$ within the lower basalt flow and extends upwards towards the ground surface as shown on Figure 2a. The model was discretized using $23 \times 21 \times 21$ nodes of dimension $1.0 \mathrm{~m} \times 1.0 \mathrm{~m} \times$ $1.0 \mathrm{~m}$ in the $x$-, $y$ - and $z$-dimensions, respectively, for each of the matrix and fracture continua. Nodes along the top of the model are reduced in thickness to conform to the irregular ground surface elevation. Connections between nodes follow a simple seven-point lattice, with both fracture- and matrix-continuum nodes connected between themselves as well as to their six adjacent nodes. The discretization was chosen to be able to represent the zonal structure of the upper basalt flow and resolve simulated water saturation profiles resulting from the infiltration experiments. Furthermore, the lateral and vertical dimensions of the model were chosen to contain the full 3-D infiltration front extending from beneath the pond (see Figure 2a) within the entire upper basalt flow without interference from boundary conditions (this will be confirmed later in this work). The above discretization yielded a combined total of 20,286 matrix- and fracture-continuum nodes, which permitted reasonable simulation times for calibration purposes (days for the full 3-D model).

Flow of water and gas occurs between the fracture and matrix continua according to the mass conservation laws discretized by TOUGH2. Specifically, the interfacial area $A_{f m i}$ between the fracture and matrix continua through which the water and gas flow is given as:

$$
A_{f m i}=2\left(\Delta y_{i} \Delta z_{i} \frac{\Delta x_{i}}{D_{H i}}+\Delta x_{i} \Delta z_{i} \frac{\Delta y_{i}}{D_{H i}}+\Delta x_{i} \Delta y_{i} \frac{\Delta z_{i}}{D_{V i}}\right)
$$

where $\Delta x_{i}=\Delta y_{i}=\Delta z_{i}=1.0 \mathrm{~m}$, which represents the size of node $i$ in the $x$-, $y$ - and $z$-directions. 


\section{Pneumatic-Test Analysis}

Pneumatic tests were conducted at the Box Canyon site to assess the permeability of the basalt (Benito et al., 1999). These tests consisted of air being injected into approximately one-meter packer intervals within slanted boreholes S-3 and S-4 as well as the vertical borehole II-5. These wells are all located within close lateral proximity of one another as shown in Figure 2a. The intent of these tests was to delineate vertical variations in the permeability of the upper basalt flow. The pneumatic tests consisted of injecting air at a constant rate within the packer interval and measuring the steady-state pressure response within the packer interval as well as in neighboring boreholes. This method has also been used extensively to characterize the permeability of the interconnected fracture network at Yucca Mountain (Huang et al., 1999). The injected air is assumed to flow entirely though the fracture network rather than the matrix, given that it is a nonwetting phase in an air-water system and prefers to reside in the larger aperatures of the fractures. In contrast, water preferentially resides in the matrix due to the stronger capillary forces within the matrix imbibing water from the fractures and keeping them dry. Furthermore, the fractures have a permeability that is orders of magnitude greater than the matrix further focusing air flow within the fracture network. The assumption that injected air flows entirely though the fracture network was necessary to allow the pneumatic tests to estimate fracturecontinuum permeability as a single unknown parameter without any a priori assumptions regarding additional parameters involved in fracture-matrix flow. The complete and final Box Canyon model (including matrix-continuum nodes) was used to re-simulate select pneumatic tests yielding similar pressure-response results, implying that the assumption was justified.

The pneumatic tests were simulated using the 3-D model in order to calibrate the permeability of the fracture-continuum nodes. To calibrate the model, we used only steady-state pressure 
responses within the injection intervals. A detailed list of all the injection intervals describing the location, injection rate and steady-state pressure response can be found in Unger et al. (2002). Calibration of the model involved initially setting the gas-phase pressure equal to $85 \mathrm{kPa}$ along the bottom boundary and decreasing statically upwards to the top boundary. Constant pressure gas-phase boundary conditions were fixed at all sides of the model. Calibration then proceeded by manually adjusting the permeability of each fracture-continuum node within which the centroid of an injection interval was located, until the model closely matched the observed field-pressure response at steady state for the applied injection rate. The average permeability of each zone within the upper basalt flow (in addition to the rubble zone and lower basalt) was calculated by taking the geometric mean permeability of all nodes within which air injection took place for each specific zone. This calibration method is only meant to estimate the mean permeability of each of the various zones and does little to determine the spatial continuity in the permeability field around boreholes S-3, S-4 and II-5. This objective was considered sufficient for the purpose of this calibration, given that an estimate for the site-wide permeability was needed in order to simulate the infiltration tests. Furthermore, we do not anticipate that the fracture network sampled by the radial flow of air away from the pneumatic test intervals is identical to that controlling downward flow of the infiltrating water. Therefore, our intent is to use the pneumatic tests to characterize the average site-wide fracture-continuum permeability with these limitations in mind. Table 2 summarizes the average permeability of each specific zone within the upper basalt flow, rubble zone and lower basalt. The average fracture aperture, permeability and porosity for each zone were calculated using the following equations:

$$
\begin{aligned}
& k_{x f i}=k_{y f i}=\frac{b_{i}^{3}}{12 D_{H i}}+\frac{b_{i}^{3}}{12 D_{V i}}, \quad k_{z f i}=\frac{b_{i}^{3}}{12 D_{H i}} \\
& \phi_{f i}=\frac{b_{i}}{D_{H i}}+\frac{b_{i}}{D_{H i}}+\frac{b_{i}}{D_{V i}}
\end{aligned}
$$


where $k_{x f i}, k_{y f i}, k_{z f i}$ are the diagonal components of the fracture permeability tensor, $b_{i}$ is the average fracture aperture for all horizontal, $H$, and vertical, $V$, fracture planes, and $\phi_{f i}$ is the fracture porosity of node $i$.

Model calibration residual values were calculated as the change in pressure observed in the field minus the change in pressure simulated in the model at the node in which injection took place. These values are tabulated in Unger et al. (2002). The RMS error, which is the mean of the sum of the squares of the residuals, is $8647 \mathrm{~Pa}$, which is larger than 22 of the 51 pneumatic pressure responses. The magnitude of the error is caused by the difficulty in matching the large pressure increase in the low-permeability injection nodes by adjusting only the permeability of the injection node along with the average value. Injection-node permeability values that were similar or higher than the average value were more accurately simulated by the model. The residual bias, calculated as the arithmetic mean of the residuals is $15962 \mathrm{~Pa}$, also indicating that the fit was poorest for injection nodes within the lowest permeabilities (that subsequently induced the largest pressure response). The RMS and residual bias errors indicate that the calibration method used is only suitable for estimating the average fracture continuum permeability and should not be interpreted as a precise fit to the data from each test.

\section{Infiltration Test Analysis}

\subsection{General Approach}

A series of ponded infiltration tests were conducted at the Box Canyon site to mimic episodic surface-flooding events that occur during large rainstorms or snowmelt events. The 96-1 ponded infiltration test was conducted between 8/27/96 to 9/9/96 and involved maintaining water at a spatially averaged depth of $23 \mathrm{~cm}$ above the uneven land surface. Potassium bromide tracer was added midway through the 96-1 test yielding an average tracer concentration in the pond of $3 \mathrm{~g} / \mathrm{l}$. 
The water supply to the pond was halted for two days so the tracer was not diluted. Thereafter, the water supply was re-established to maintain a constant water level. Next, four separate infiltration events called 97-1, 97-2, 97-3 and 97-4 were conducted between 9/11/97 to 11/3/97. In each of these tests, a fixed volume of water containing $3 \mathrm{~g} / 1$ of potassium bromide was allowed to infiltrate over a 2-4 day interval before the remaining solution was pumped out to allow ambient air to enter the subsurface. Details concerning the infiltration experiments can be found in Faybishenko et al. (1998a, 1999). The starting time, duration and infiltration rates measured during the ponding events are provided in Table 3.

Hydrogeological characterization of the basalt matrix was conducted by Knutson et al. (1990), who measured the permeability and porosity of core samples. Samples with high porosities, obtained from vesicular regions of the matrix, yielded permeability values greater than $1 \times 10^{-12}$ $\mathrm{m}^{2}$ and exceeded the maximum range capable of being reliably measured by their experimental design. The arithmetic mean porosity of the core samples was $19.2 \%$, and the geometric mean permeability was $2.24 \times 10^{-15} \mathrm{~m}^{2}$. These values are biased towards the more impermeable and low porosity regions of the basalt because measurements from the vesicular zone were not included. All matrix continuum nodes the 3-D Box Canyon numerical model were assigned the arithmetic mean porosity and the geometric mean permeability.

Boundary conditions applied to the numerical model for simulating the infiltration experiments consisted of a constant gas-phase pressure of $85 \mathrm{kPa}$ along the bottom of the model, which then decreased statically upwards. All sides of the model were constrained as constant gas-phase pressure boundary conditions by using large-volume nodes. An infiltration rate of $0.01 \mathrm{~m} / \mathrm{yr}$ resulting from recharge was used to establish the steady-state water saturation profile (Cecil et al., 1992). This resulted in a steady-state water-phase pressure and saturation distribution within the 
fracture and matrix continua in equilibrium with the specified gas-phase pressure and infiltration rate. The steady-state water- and gas-phase pressure and saturation profiles were used as initial conditions for all subsequent simulations with all boundary conditions enforced using largevolume nodes. For the infiltration test simulations, the slightly irregular nature of the infiltration pond was approximated to fit within coordinates $(58 \mathrm{~m} \mathrm{E}, 60 \mathrm{~m} \mathrm{~N})$ to $(67 \mathrm{~m} \mathrm{E}, 69 \mathrm{~m} \mathrm{~N})$ in order to conform to the regular nature of the grid. Infiltration of the ponded water was simulated by draping a layer of high-permeability fracture-continuum nodes over the ground surface within the perimeter of the infiltration pond. This layer conformed to the irregular ground surface elevation shown in Figure 2a. Water was then injected into each of these draped nodes at the rate observed during each infiltration event (Faybishenko et al., 1999), as specified in Table 3. This water was then able to redistribute itself horizontally within the high-permeability layer before infiltrating into the fracture-continuum nodes of the Box Canyon model. This infiltration proceeded according to variations in the ground surface elevation. The constant-pressure gas-phase boundary condition was removed from all nodes within the perimeter of the pond.

Calibration of the model to the infiltration test data followed three main steps. First, bromide concentration data collected from active water-conducting features was used to infer the first detectable arrival of the infiltration front during the 97-1 to 97-4 infiltration tests as described in Section 5.2. Second, one-dimensional columns of nodes located beneath the infiltration pond and containing the active water-conducting fractures were used to calibrate fracture-continuum porosity, fracture-matrix continua interfacial area, and matrix-continuum permeability. Specifically, these parameters were calibrated from two sampling depths in borehole I-1 and were then verified by direct application to boreholes I-2 and T-5 in Section 5.3. Third, the full threedimensional model was used with parameters obtained from the 1-D calibration effort to verify the arrival time of the infiltration front in boreholes E-4 and T-4 in Section 5.4. These boreholes 
are located outside of the perimeter of the infiltration pond. Details concerning these three steps are given below.

\subsection{Use of Bromide Concentration Data to Infer Infiltration Front Arrival Times}

The arrival times of the infiltration front were inferred from the first significant increase in bromide concentration in water samples taken as part of the tracer tests conducted during each infiltration test. Therefore, it was assumed that the bromide tracer was conservative and advected at the same velocity as the infiltration front in the fracture continuum. Note that the bromide data were used to constrain parameters controlling variably saturated groundwater flow. Advectivedispersive transport of bromide was not simulated within the variably saturated flow field.

Tracer tests conducted during the 97-1 to 97-4 series of infiltration tests provided the most comprehensive set of bromide measurements and consequently were used during the calibration. Because a bromide tracer test was conducted in 96-1, a background concentration of bromide existed prior to the start of the 97-1 test as tabulated in Unger et al. (2002). Statistical analysis of the data indicated that they were log-normally distributed with a mean of $4.35 \ln (\mathrm{mg} / \mathrm{l})$ (or 77.48 $\mathrm{mg} / \mathrm{l})$ and a standard deviation of $0.94 \mathrm{ln}(\mathrm{mg} / \mathrm{l})$. Given these statistics, a bromide concentration of $240 \mathrm{mg} / 1$ provided an $88.5 \%$ confidence interval for the bromide concentration being significantly greater than the mean background concentration. Therefore, the first sampling event when the bromide concentration exceeded $240 \mathrm{mg} / \mathrm{l}$ was used to infer the infiltration-front arrival at that sampling point by being the first significant increase in bromide concentration above background values within an $88.5 \%$ confidence interval. This inference assumes that dilution of the bromide tracer at the infiltration front because of dispersion and losses into the matrix continuum did not attenuate the transport of bromide concentration of 0.1 of the source value behind the infiltrationfront advection rate. These times are listed as the maximum bromide arrival time in Table 4 . The sampling time immediately prior to when bromide exceeded $240 \mathrm{mg} / \mathrm{l}$ is listed as the minimum 
bromide arrival time in Table 4. Together, the maximum and minimum provide a window on the expected infiltration-front arrival time at the sampling point. In some cases, the first bromide sample exceeded a concentration of $240 \mathrm{mg} / \mathrm{l}$, setting the maximum value on the time window, but no prior sample was taken to set the minimum value on the window. In this case, the minimum arrival time of the infiltration front was set by default as the start of the 97-1 infiltration test. Although we expect that the maximum bromide arrival time is a conservative estimate of the infiltration front arrival, verification of this assumption requires detailed flow and transport modeling in individual rough-walled fractures. Given the conservative nature of this assumption, we expect parameters derived from its use to underestimate (to some degree) the infiltration rate of water at the Box Canyon site.

\subsection{Calibration Using Infiltration Front Arrival Times}

Calibration of the model was performed by extracting 1-D vertical columns from beneath the infiltration pond where the 97-1 bromide data indicated borehole intersections with fractures that actively conducted water. It was thus assumed that the infiltration front in the full 3-D model progressed downward in a 1-D manner along vertical columnar fractures to each sampling point. Calibration involved the use of the 1-D columns rather than the full 3-D model to significantly reduce simulation times. Discretization of the 1-D columns consisted of the same $1.0 \mathrm{~m}^{3}$ blocks used to discretize the site model. Although numerical accuracy in terms of resolving the water saturation in the fracture continuum at the infiltration front could be significantly improved with a finer discretization, discretization of the columns was identical to the site model. This allowed calibration parameters to be transferred directly to the site model and prevent concerns regarding scaling issues. Infiltration at the rate prescribed in Table 3 was applied to the top fracturecontinuum node of each column. 
Parameter estimation was performed manually. Consequently, only a qualitative analysis of a given parameter's sensitivity to the overall calibration process is provided. A systematic calibration effort using an inverse model such as ITOUGH2 (Finsterle, 1999) would provide a better understanding of the interrelationship of parameters assumed to control preferential flow paths of infiltrating water in the fractured basalt at Box Canyon. The focus of this work is to establish a preliminary method for interpreting the Box Canyon data set. This is a necessary stage of the model development, enabling us to obtain meaningful parameters from inverse modeling.

Calibration was initially performed by matching infiltration-front arrival times at borehole I-1 at vertical depths of $1.5 \mathrm{~m}$ and $10.1 \mathrm{~m}$ below the ground surface. Calibration proceeded in three steps. First, the fracture-continuum porosity as calculated from the fracture aperture from Table 2 and by Equation (3) was manually scaled. Second, the matrix-continuum permeability was adjusted. Third, the fracture-matrix interfacial area given by Equation (1) was scaled. These three steps in the calibration procedure were conducted iteratively until the calibration objective was reached.

Justification for scaling the fracture-continuum porosity is based on fractures having rough walls, creating an irregular aperture distribution. Fractures may have many dead-end channels that contribute to tortuous flow of the infiltrating water through the fracture plane. Furthermore, scaling the porosity may accommodate differences in the equivalent aperture of the fracture continuum node as inferred from the pneumatic tests and subsequently applied to represent the infiltration of the water phase and the bromide tracer test data. Increasing the fracture porosity acts to slow down the rate at which the infiltration front advects through the fracture continuum.

Matrix permeability was adjusted to account for large-scale vesicular zones distributed throughout the basalt matrix. These act to increase permeability of the matrix continuum at the 
$1.0 \mathrm{~m}^{3}$ scale of the nodes relative to the core scale. Increasing matrix permeability acts to slow down the rate at which the infiltration front advects through the fracture continuum because the matrix continuum is also able to conduct a portion of the infiltrating water. Increasing matrix permeability also acts to dampen the increase in water saturation at the infiltration front, attenuating its migration rate, because the matrix then responds more rapidly to the flow of water from the fracture continuum. This flow of water occurs because the capillary pressure within the fracture continuum decreases substantially at the infiltration front where the water saturation approaches unity. The capillary pressure, along with the water saturation in the matrix continuum, changes much more slowly than in the fracture continuum because of the large matrix storage capacity. The difference in capillary pressure, caused by the disequilibrium in the fracture and matrix continua, then causes the flow of water from the fracture into the matrix continuum.

The fracture-matrix interfacial area given by Equation (1) was scaled downwards by a constant factor to decrease the exchange of water between the fracture and matrix continuum nodes at the infiltration front resulting from the influence of capillary forces. This parameter is expected to be small, given that channelized flow of water is observed to occur in fractures (Pruess, 1999; Su et al., 1999). This implies significantly less contact area for water between the fracture and matrix continua than if sheet flow were to occur in the fracture plane. Reduction in interfacial area acts to decrease the influence of the matrix continuum on the fracture continuum, thereby increasing the rate at which the infiltration front advects in the fracture continuum.

Imbibition of water from the fracture into the matrix continua during the infiltration pluses is primarily a function of the water saturation prior to the 97-1 test. Figure 4 shows this water saturation profile for borehole I-1 calculated using both van Genuchten and Corey relative permeability curves with a residual water saturation of $S_{l r}=0.01$ and $S_{l r}=0.1$ in the fracture and matrix continua, respectively; van Genuchten $m$ values are given on Table 5 . The form of these 
functions for both the fracture and matrix continua as implemented in TOUGH2 (Pruess, 1987, p.74) are:

Corey

$$
\begin{aligned}
& S^{*}=\left(S_{l}-S_{l r}\right) /\left(1-S_{l r}-S_{g r}\right) \\
& k_{r l}=\left(S^{*}\right)^{4} \\
& k_{r g}=\left(1-S^{*}\right)^{2}\left(1-\left[S^{*}\right]^{2}\right)
\end{aligned}
$$

van Genuchten

$$
\begin{aligned}
& S^{*}=\left(S_{l}-S_{l r}\right) /\left(S_{l s}-S_{l r}\right) \\
& k_{r l}=\left\{\begin{array}{l}
\sqrt{S^{*}}\left\{1-\left(1-\left[S^{*}\right]^{1 / m}\right)^{m}\right\} \text { if } S_{l}<S_{l s} \\
1 \quad \text { if } S_{l} \geq S_{l s}
\end{array}\right. \\
& k_{r g}=1-k_{r l}
\end{aligned}
$$

where $k_{r l}$ and $k_{r g}$ are the relative permeability of the liquid and gas phases, respectively. $S_{l s}$ is the maximum liquid saturation in either the fracture or matrix continua and was assumed equal to unity, and $S_{g r}$ is the residual gas saturation and was assumed equal to zero in both the fracture and matrix continua. Given the significant difference in water saturation shown on Figure 4, we expect the interfacial area required to control imbibition of the infiltrating water to vary significantly as well. At present, there are no water saturation or relative permeability data to constrain the influence of uncertainty in the form of the relative permeability function on the calibrated interfacial area scaling factor. Therefore, we adopt the van Genuchten relative permeability function in analogy to the Yucca Mountain studies, but also present calibration results using the Corey function as part of a sensitivity analysis. Capillary pressure in both the variably saturated matrix and fracture continuum nodes was represented using van Genuchten functions as implemented in TOUGH2 (Pruess, 1987, p.77) with $\alpha$ and $m$ parameters provided in Table 5. Although no formal capillary pressure--water saturation data has been obtained to 
characterize either the fractures or basalt matrix at Box Canyon, this choice of parameters yielded capillary pressures in the range of $10 \mathrm{kPa}$ to $50 \mathrm{kPa}$, which was consistent with tensiometer measurements from the site (Faybishenko et al., 1998a, 1999).

Calibration results for borehole I-1 are shown in Figure 5, which shows the change in water saturation in the fracture- and matrix-continuum nodes as a function of time where the time datum is the start of the 96-1 infiltration test. Sampling point I-1 at a depth of $1.5 \mathrm{~m}$ shows a rapid water saturation change within the time window specified by the bromide data. This response occurred immediately after the 97-1 test, indicating that the infiltration front advected rapidly through the fracture continuum near the ground surface. Sampling point I-1 at a depth of $10.1 \mathrm{~m}$ also responds within the time window specified by the bromide data, although the response does not occur until during the 97-2 infiltration test. All of the water that had infiltrated from the 97-1 test was completely absorbed from the fracture into the matrix-continuum nodes before the infiltration front could reach a depth of $10.1 \mathrm{~m}$. It wasn't until during the 97-2 test that a sufficient increase in water saturation relative to steady-state conditions existed in the matrix to allow the infiltration front to propagate to a greater depth.

Fracture- and matrix-continuum properties obtained during the calibration for borehole I-1 are given in Table 5. Of particular note is that the fracture porosity was scaled upwards by a factor of 50 relative to the fracture porosity from the permeability calibration exercise. Porosity was an extremely sensitive parameter, controlling the infiltration rate of water in the fracture continuum. The resulting fracture-continuum porosity for the upper basalt ranged from 0.01 to 0.02 . Dunnivant et al. (1998) calculated a porosity of 0.02 based on the observed infiltration rate and travel rate of the infiltration front for the LPIT. This adds credibility to this calibration effort given that both the Box Canyon and the LPIT infiltration test were conducted independently within similar fractured-basalt settings at the INEEL. The matrix permeability was increased by a 
factor of 4.5 to reflect the presence of vesicular zones distributed throughout the upper basalt. This adjustment is within an order-of-magnitude of values obtained from core samples indicating that the vesicuar regions of the matrix did not conduct significantly more water than nonvesicular regions represented by the core measurements. The fracture-matrix interfacial area was scaled by a factor of 0.01 and 0.1 using the Corey and van Genuchten relative permeability functions, respectively, to allow the matrix to completely absorb the 97-1 infiltration front between a depth of $1.5 \mathrm{~m}$ and $10.1 \mathrm{~m}$, while allowing the 97-2 infiltration front to propagate to a depth of $10.1 \mathrm{~m}$. Despite uncertainty in the form of the relative permeability function and the resulting steady-state water saturation distribution, identical calibration results in terms of fracture-continuum porosity and matrix-continuum permeability were obtain but with interfacial area varying by an order-of-magnitude. This underscores the non-uniqueness of the calibration results and the need to obtain water saturation and relative permeability data to constrain the interfacial area scaling factor. Despite this non-uniqueness, both fracture-continuum porosity and matrix-continuum permeability values were representative of independently measured values. Therefore, we expect that they are within a physically justifiable range of measurement error and additional water saturation and relative permeability data could be used to focus on reducing uncertainty in the fracture-matrix interfacial area.

The possibility of non-uniqueness existed during the calibration of the I-1 column because three parameters were adjusted to calibrate the model to the arrival time of an infiltration front at two different depths. The possibility of non-uniqueness is addressed by determining whether parameters used to calibrate I-1 are capable of predicting infiltration front arrival times at other sampling locations where bromide data are available.

Figure 6 shows calibration results for sampling intervals within borehole I-2 using hydrogeological parameters estimated from the I-1 calibration. The only sampling point in 
borehole I-2 that has both a minimum and maximum expected arrival time occurs at a depth of $6.1 \mathrm{~m}$. The minimum arrival time occurs 0.3 days after the start of the $97-1$ test, and the maximum occurs only 0.2 days after the start of the 97-2 test. Examination of Figure 6 shows that the majority of the simulated infiltration water from the 97-2 test is absorbed into the matrix before the start of the 97-2 test, although a small increase in water saturation does reach a depth of $6.1 \mathrm{~m}$ when using both Corey and van Genuchten relative permeability functions. This is the remnant of a severely attenuated infiltration front from the 97-1 test. At the start of the 97-2 test, the water saturation rapidly increases after 0.2 days, although the peak saturation of the infiltration front arrives shortly after the maximum expected arrival time for both Corey and van Genuchten functions. In general, these parameters do capture the rapid arrival of water after the start of the 97-2 test (although decreasing the porosity multiplier given in Table 5 could accelerate the arrival time).

Figure 7 shows the arrival time of the infiltration front for borehole T-5 at a depth of $3.0 \mathrm{~m}$. Bromide data indicated that the maximum and minimum expected arrival times of the infiltration front did not occur until after the start of the 97-3 test. Examination of the simulated arrival times shows the model predicting infiltration-front arrival after the 97-2 test when using both Corey and van Genuchten functions. This implies that the fracture-matrix interfacial area may have been significantly higher for the columnar fracture extending downwards to borehole T-5 at a sampling depth of $3.0 \mathrm{~m}$, causing both the 97-1 and 97-2 test infiltration fronts to be absorbed into the matrix. Alternatively, the fracture pathway may not have been an active conduit for water during one or both of the 97-1 and 97-2 tests. This behavior is analogous to that of the LPIT where preferential flow paths of infiltrating water and tracer transport were observed. Borehole T-5 indicates that the dual-permeability simplification can only approximate the behavior of flow in discrete fractures 
Maximum expected infiltration-front arrival times located directly beneath the pond were also obtained for boreholes I-2 (at sampling depths of $0.3 \mathrm{~m}, 1.5 \mathrm{~m}$ and $3.0 \mathrm{~m}$ ), T-6, T-7, T-8, T-9, E-1 and I-3. These data were not included during the calibration because they did not include a minimum expected arrival time to establish a time window. The maximum times alone did not help refine the parameter calibration or provide additional insight into preferential flow paths of infiltrating water beyond the data already used in this section.

\subsection{Three-Dimensional Model Simulation}

Following the 1-D calibration exercise, the full 3-D site model was used to examine infiltration front arrival times in boreholes E-4 and T-4 at sampling depths of $3.5 \mathrm{~m}$ and $5.8 \mathrm{~m}$, respectively. These locations had bromide data indicating both minimum and maximum expected infiltrationfront arrival times and were outside the perimeter of the infiltration pond. Hence, the full 3-D infiltration front extending from beneath the pond was simulated to capture the lateral migration of the infiltrating water to these observation points. Use of the full 3-D model serves as confirmation regarding the applicability of parameters obtained during the 1-D calibration exercise. Due to the computational effort involved in the 3-D simulation, we only present results using the Corey relative permeability function because it significantly outperformed the van Genuchten function in terms of the numerical efficiency of the Newton iteration. Given that both functions yielded consistent results with respect to the 1-D columns, we expect similar behavior for the 3-D model simulation.

Figure 8 shows the simulated water-saturation distribution in the fracture continuum at 0.9 days into the 97-2 infiltration test (388 days since 96-1). This time was chosen because it roughly coincided with the arrival time of the infiltration front for sampling depths between $3.0 \mathrm{~m}$ and 6.0 $\mathrm{m}$ from the 1-D analysis. These depths are in the range of sampling depths in boreholes E-4 and T-4. In addition, this time is before the minimum expected time of infiltration-front arrival for E- 
4 and T-4 that occurred 1.93 days into the $97-2$ infiltration test (389.03 days since $96-1)$. The simulated region of elevated water saturation resulting from the infiltrating water is quite laterally uniform, although the irregular ground surface elevation does preferentially focus infiltration of the ponded water into depressions within the perimeter of the pond. This is shown by regions of elevated water saturations in the eastern half of the pond. Figure $8 \mathrm{~b}$ shows that the infiltration front, as given by elevated water saturations relative to background values, has just reached E-4 at a depth of $3.5 \mathrm{~m}$. Figure $8 \mathrm{c}$ shows the infiltration front arriving at T-4 at a depth of $5.8 \mathrm{~m}$. Hence, parameters obtained from the 1-D calibration do predict the correct minimum arrival time of the infiltration front within the 3-D model for boreholes located outside the perimeter of the infiltration pond.

Figure 9 shows the simulated water saturation distribution 2.9 days (390 days since 96-1) into the 97-2 infiltration test. This time was chosen because it occurred just after the maximum expected time for the arrival of the infiltration front at borehole T-4 and within the time window for E-4. Figure 9 shows that the water migrated laterally to boreholes E-4 and T-4 at sampling depths of $3.5 \mathrm{~m}$ and $5.8 \mathrm{~m}$, respectively, indicating that the infiltration front arrived before the maximum expected time inferred from the bromide data.

In the context of this Box Canyon model, the lateral migration of the infiltration front is predominately a consequence of capillary forces acting over the scale of the fracture and matrix continuum nodes. These forces disperse the sharp water saturation gradients along the edge of the infiltration front directly beneath the pond. The mechanism controlling the arrival of the infiltrating water at these locations in the field may also be a function of tortuous pathways for the water rivulets in the rough-walled fractures. This flow process cannot be exactly represented at the scale of the fracture-continuum nodes in the model. Instead, it is approximated by the small fracture-continuum porosity and reduced fracture-matrix continuum interfacial area. Given that 
the correct infiltration-front arrival times were predicted for boreholes E-4 and T-4, this approximation appears reasonable for representing measured flow processes occurring in the fractured basalt.

\section{Summary and conclusions}

A series of ponded infiltration tests at Box Canyon, Idaho, were simulated to examine the applicability of the dual-permeability modeling approach for representing flow processes in the variably saturated, fractured basalt present at the site. Construction of the Box Canyon conceptual model involved subdividing the upper basalt flow into zones based upon the vertical columnar fracture spacing. The hydrogeological system at Box Canyon was then simulated using TOUGH2. Calibration of the model proceeded in two stages. First, the permeability of the fracture continuum nodes was adjusted to reflect the pressure response from pneumatic tests conducted at the site. Second, arrival times of the infiltration front as inferred from the bromide tracer data were used to calibrate the fracture-continuum porosity, matrix-continuum permeability, and fracture-matrix-continua interfacial area.

Calibration results indicated that the fracture-continuum porosity was a very sensitive parameter, controlling the arrival time of the infiltration front. The fracture-continuum porosity of the upper basalt flow was increased by a factor of 50 relative to that calculated using the aperture from the permeability calibration. The resulting fracture-continuum porosity for the upper basalt ranged from 0.01 to 0.02 . This is similar to that estimated for the LPIT which yielded a porosity of 0.02 (Dunnivant et al., 1998). The matrix-continuum permeability was increased by a factor of 4.5 relative to the core measurements to reflect the influence of the highly permeable vesicular zones on the field scale. This adjustment is within an order-of-magnitude of values obtained from core samples indicating that the vesicular regions of the matrix did not conduct significantly more 
water than the non-vesicular regions of the matrix represented by the core samples. Finally, the interfacial area between the fracture and matrix continua were multiplied by a factor of 0.01 and 0.1 when using the Corey and van Genuchten relative permeability functions, respectively. This caused the 97-1 infiltration pulse to be completely absorbed from the fracture into the matrix continuum at a shallow depth while permitting the 97-2 infiltration pulse to advect rapidly to a greater depth. Identical calibration results in terms of fracture-continuum porosity and matrixcontinuum permeability but with interfacial area varying by an order-of-magnitude imply that there is non-uniqueness in the calibration results. Despite this non-uniqueness, both fracturecontinuum porosity and matrix-continuum permeability values were representative of independently measured values. Therefore, we expect that they are within a physically-justifiable range of measurement error and additional water saturation and relative permeability data could be used to focus on reducing uncertainty in the fracture-matrix interfacial area.

Simulation of the infiltration front using the 3-D model for the Box Canyon site with parameters from the 1-D analysis indicates that the infiltration front reaches boreholes T-4 and E-4 just before the minimum expected arrival time given by the bromide data. These boreholes are located outside the perimeter of the pond, implying that the advection of the 3-D infiltration front as predicted by the model is consistent with the field data.

\section{Acknowledgments}

This work was supported by the Director, Office of Civilian Radioactive Waste Management, U.S. Department of Energy, through Memorandum Purchase Order EA9013MC5X between Bechtel SAIC Company, LLC and the Ernest Orlando Lawrence Berkeley National Laboratory (Berkeley Lab). The support is provided to Berkeley Lab through the U.S. Department of Energy Contract No. DE-AC03-76SF00098. We thank Tom Wood and Tom Stoops of the INEEL, who 
were participants in the 1996-1998 Box Canyon experiments, for their encouragement in our application of Box Canyon data as a natural analog to Yucca Mountain. We also appreciate the efforts of Pascual Benito of LBNL in reducing some of the Box Canyon data for our application and Marianne Guerin, Mark Bandurraga, and Peter Persoff of LBNL, Swen Magnuson of the INEEL, as well as an anonymous reviewer who provided technical reviews of this manuscript. 


\section{References}

Bandurraga, T. M., Bodvarsson, G.S., 1999. Calibrating hydrogeologic parameters for the 3-D site-scale unsaturated zone model of Yucca Mountain, Nevada., Journal of Contaminant Hydrology, 38, 25-46.

Barenblatt, G.E., Zheltov, I.P., Kochina, I.N., 1960. Basic concepts in the theory of seepage of homogeneous liquids in fissured rocks., J. Appl. Math 24(5), 1286-1303.

Benito, P. H., Cook. P., Faybishenko, B., Freifeld, B., Doughty, C., 1999. Cross-well air-injection packer tests for the assessment of pneumatic connectivity in fractured, unsaturated basalt., Rock Mechanics for Industry, B. Amadei, R.L. Kranz, G.A. Scott and P.H. Smeallie, eds., Proceedings of the $37^{\text {th }}$ U.S. Rock Mechanics Symposium, Vail, Colorado.

Cecil, L.D., Pittman, J.R., Beasley, T.M., Michel, R.L., Kubik, P.W., Sharma, P., Fehn, U., Grove, H., 1992. Water infiltration rates in the unsaturated zone at the Idaho National Engineering Laboratory estimated from Chlorine-36 and Tritium profiles, and neutron logging., Y.K. Kharaka and A.S. Meest, eds., Proceedings of the $7^{\text {th }}$ International Symposium on Water-Rock Interaction, Park City, Utah.

Dean, R. and L. Lo, 1988. Simulation of naturally fractured reservoirs. SPE Reservoir Eng., 638648.

Doughty, C., 1999. Investigation of conceptual and numerical approaches for evaluating moisture, gas, chemical and heat transport in fractured unsaturated rock., Journal of Contaminant Hydrology, 38, 69-106.

Dunnivant, F.M., Newman, M.E., Bishop, C.W., Burgess, D., Giles, J.R., Higgs, B.D., Hubbell, J.M., Neher, E., Norrell, G.T., Pfiefer, M.C., Porro, I., Starr, R.C., Wylie, A.H., 1998. Water and radioactive tracer flow in a heterogeneous field-scale system., Ground Water, 36(6), 949-958. 
Faybishenko, B., Salve, R., Zawislanski, P., Doughty, C., Lee, K.H., Cook, P., Freifeld, B., Jacobsen, J., Sisson, B., Hubbell, J., Dooley, K., 1998a. Ponded infiltration test at the Box Canyon Site-Data report and preliminary analysis., Rep. LBNL-40183, Lawrence Berkeley Laboratory, Berkeley, CA.

Faybishenko, B., Holland, P., Mesa, M., Burgess, D., Knutson, C., Sisson, B., 1998b. Lithological conditions at the Box Canyon Site: Results of drilling, coring and open borehole measurements-1995-1997 data report., Rep. LBNL-40182, Lawrence Berkeley Laboratory, Berkeley, CA.

Faybishenko, B., Doughty, C., Steiger, M., Long, J.C.S., Wood, T.R., Jacobsen, J.S., Lore, J., Zawislanski, P.T., 1999. Conceptual model of the geometry and physics of water flow in a fractured basalt vadose zone: Box Canyon Site, Idaho., Rep. LBNL-42925, Lawrence Berkeley Laboratory, Berkeley, CA.

Finsterle, S., 1999. ITOUGH2 User's Guide, Rep. LBNL-40040, Lawrence Berkeley National Laboratory, Berkeley, CA.

Grossenbacher, K., Faybishenko, B., 1995. Spacing of thermally induced columnar joints in basalt: Variation with depth., Rep. LBNL-38060, Lawrence Berkeley Laboratory, Berkeley, CA.

Huang, K., Tsang, Y.W., Bodvarsson, G.S., 1999. Simultaneous inversion of air injection tests in fractured unsaturated tuff at Yucca Mountain, Water Resour. Res., 35(8), 2375-2386.

Knutson, C.F., McCormick, K.A., Smith, R.P., Hackett, W.R., O'Brien, J.P., Crocker, J.C., (July) 1990. FY 89 Report RWMC Vadose Zone Basalt Characterization, informal report prepared for the U.S. Department of Energy, Idaho Operations Office, DOE Contract No. DE-AC07-76ID01570, prepared by EG\&G Idaho, Inc.

Knutson, C.F., Cox, D.O., Dooley, K.J., Sisson, J.B., 1993. Characterization of low permeability media using outcrop measurements., in $68^{\text {th }}$ Annual Technical Conference and Exhibition 
of the Society of Petroleum Engineers., October 3-6, 1993, Houston TX., SPE Paper 26487.

Liu, H. H., Doughty, C., Bodvarsson, G.S., 1998. An active fracture model for unsaturated flow and transport in fractured rocks., Water Resour. Res., 34(10), 2633-2646.

Magnuson, S., 1995. Inverse modeling for field-scale hydrologic and transport parameters of fractured basalt., Rep. INEL-95/0637, Idaho National Engineering Laboratory, Idaho Falls, Idaho.

McLaren, R.G., P.A. Forsyth, E.A. Sudicky, J.E. VanderKwaak, F.W. Schwartz and J.H. Kessler, 2000. Flow and transport in fractured tuff at Yucca Mountain: numerical experiments on fast preferential flow mechanisms., Journal of Contaminant Hydrology., 43, 211-238.

Pruess, K., Faybishenko, B., Bodvarsson, G.S., 1999. Alternative concepts and approaches for modeling flow and transport in thick unsaturated zones of fractured rocks., Journal of Contaminant Hydrology., 38, 281-322.

Pruess, K., 1999. A mechanistic model for water seepage through thick unsaturated zones in fractured rocks of low matrix permeability., Water Resour. Res., 35(4), 1039-1057.

Pruess, K., 1991. TOUGH2 - A general-purpose numerical simulator for multiphase fluid and heat flow., Rep. LBNL-29400, Lawrence Berkeley Laboratory, Berkeley, CA.

Pruess, K., 1987. TOUGH User's Guide., Rep. LBNL-20700, Lawrence Berkeley Laboratory, Berkeley, CA.

Pruess, K., Narasimhan, T.N., 1985. A practical method for modeling fluid and heat flow in fractured porous media., Society of Petroleum Engineers Journal, 25(1), 14-26.

Su, G.W., Geller, J.T., Pruess, K., Wen, F., 1999. Experimental studies of water seepage and intermittent flow in unsaturated, rough-walled fractures., Water Resour. Res., 35(4), $1019-1037$.

Unger, A.J.A., B. Faybishenko, G.S. Bodvarsson and A.M. Simmons, 2002. A three-dimensional model for simulating ponded infiltration tests in the variably saturated fractured basalt at 
the Box Canyon Site, Idaho., Rep. LBNL-44633, Lawrence Berkeley Laboratory, Berkeley, CA.

Whelan, J.A., Reed, M.F., 1997. Geostatistical analysis of regional hydraulic conductivity variations in the Snake River Plain aquifer, eastern Idaho., GSA Bulletin, 109(7), 855868. 


\begin{tabular}{|c|c|c|}
\hline Zone & $\boldsymbol{D}_{\boldsymbol{H}}(\mathbf{m})$ & $\boldsymbol{D}_{\boldsymbol{V}}(\mathbf{m})$ \\
\hline $0.0-0.2$ & 1.0 & 1.0 \\
\hline $0.2-0.4$ & 2.0 & 1.0 \\
\hline $0.4-0.6$ & 3.0 & 1.0 \\
\hline $0.6-0.8$ & 4.0 & 1.0 \\
\hline $0.8-1.0$ & 2.0 & 1.0 \\
\hline Rubble zone & 0.1 & 0.1 \\
\hline Lower basalt & 2.0 & 1.0 \\
\hline
\end{tabular}

Table 1: Zonal fracture spacing.

\begin{tabular}{|c|c|c|c|c|}
\hline Zone & $\begin{array}{c}\text { Number of } \\
\text { Samples }\end{array}$ & $\begin{array}{c}\text { Fracture } \\
\text { Permeability } \\
\left(\mathbf{m}^{\mathbf{2}}\right)\end{array}$ & $\begin{array}{c}\text { Fracture } \\
\text { Aperture } \\
\mathbf{( m )}\end{array}$ & $\begin{array}{c}\text { Fracture } \\
\text { Porosity } \\
(-)\end{array}$ \\
\hline $0.0-0.2$ & 2 & $1.0 \times 10^{-13}$ & $8.5 \times 10^{-5}$ & $2.6 \times 10^{-4}$ \\
\hline $0.2-0.4$ & 6 & $4.1 \times 10^{-13}$ & $1.5 \times 10^{-4}$ & $3.0 \times 10^{-4}$ \\
\hline $0.4-0.6$ & 12 & $4.0 \times 10^{-13}$ & $1.6 \times 10^{-4}$ & $2.7 \times 10^{-4}$ \\
\hline $0.6-0.8$ & 14 & $1.9 \times 10^{-13}$ & $1.2 \times 10^{-4}$ & $1.8 \times 10^{-4}$ \\
\hline $0.8-1.0$ & 9 & $1.1 \times 10^{-12}$ & $2.1 \times 10^{-4}$ & $4.2 \times 10^{-4}$ \\
\hline rubble zone & 1 & $1.1 \times 10^{-9}$ & $8.6 \times 10^{-4}$ & $2.6 \times 10^{-4}$ \\
\hline lower basalt & 7 & $3.5 \times 10^{-10}$ & $1.3 \times 10^{-3}$ & $2.6 \times 10^{-2}$ \\
\hline
\end{tabular}

Table 2: Fracture permeability calibration results from the analysis of the pneumatic test data. 


\begin{tabular}{|c|c|c|c|}
\hline \multicolumn{2}{|c|}{ Infiltration Test } & \multirow{2}{*}{$\begin{array}{l}\text { Time since 96-1 } \\
\text { (days) }\end{array}$} & \multirow{2}{*}{$\begin{array}{c}\text { Infiltration Rate } \\
\text { (m/day) }\end{array}$} \\
\hline Test & $\begin{array}{c}\text { Time } \\
\text { (start-end) }\end{array}$ & & \\
\hline \multirow[t]{11}{*}{$96-1$} & \multirow[t]{11}{*}{$8 / 27 / 9612: 27$} & 0.00 & 0.110 \\
\hline & & 0.50 & 0.100 \\
\hline & & 1.00 & 0.095 \\
\hline & & 1.50 & 0.085 \\
\hline & & 2.00 & 0.080 \\
\hline & & 2.50 & 0.075 \\
\hline & & 3.00 & 0.065 \\
\hline & & 3.50 & 0.06 \\
\hline & & 4.00 & 0.054 \\
\hline & & 4.50 & 0.050 \\
\hline & & 12.94 & 0.030 \\
\hline \multirow[t]{6}{*}{$97-1$} & \multirow[t]{5}{*}{ 9/11/97 12:15 } & 379.99 & 0.100 \\
\hline & & 380.24 & 0.075 \\
\hline & & 380.49 & 0.060 \\
\hline & & 380.99 & 0.040 \\
\hline & & 381.49 & 0.030 \\
\hline & & 382.01 & 0.025 \\
\hline \multirow[t]{8}{*}{$97-2$} & \multirow[t]{7}{*}{ 9/18/97 14:56 } & 387.10 & 0.175 \\
\hline & & 387.23 & 0.120 \\
\hline & & 387.35 & 0.800 \\
\hline & & 387.48 & 0.060 \\
\hline & & 387.60 & 0.045 \\
\hline & & 387.85 & 0.035 \\
\hline & & 388.10 & 0.030 \\
\hline & & 389.18 & 0.025 \\
\hline \multirow[t]{4}{*}{$97-3$} & \multirow[t]{3}{*}{ 10/2/97 15:40 } & 401.13 & 0.065 \\
\hline & & 401.63 & 0.045 \\
\hline & & 402.13 & 0.030 \\
\hline & \multirow{2}{*}{$\frac{10 / 4 / 9716: 00}{10 / 31 / 9713: 51}$} & 403.15 & 0.025 \\
\hline \multirow[t]{3}{*}{$97-4$} & & 430.06 & 0.040 \\
\hline & & 432.06 & 0.030 \\
\hline & 11/3/97 15:00 & 433.11 & 0.025 \\
\hline
\end{tabular}

Table 3: Ponding test times and infiltration rates. 


\begin{tabular}{|c|c|c|c|c|c|}
\hline \multirow[t]{2}{*}{ Well ID } & \multirow{2}{*}{$\begin{array}{c}\text { Vertical } \\
\text { Depth } \\
\text { (m) }\end{array}$} & \multicolumn{2}{|c|}{$\begin{array}{c}\text { Maximum Br- Arrival Time } \\
\mathrm{Br}^{-}>240 \mathrm{mg} / \mathrm{L}\end{array}$} & \multicolumn{2}{|c|}{ Minimum $\mathrm{Br}^{-}$Arrival Time } \\
\hline & & (date) & (days) & (date) & (days) \\
\hline E-1 & 1.50 & 9/12/97 10:29 AM & 0.93 & - & - \\
\hline E-4 & 3.50 & 9/25/97 5:32 PM & 14.22 & 9/20/97 1:10 PM & 9.04 \\
\hline \multirow[t]{4}{*}{$\mathrm{I}-1$} & 1.50 & 9/12/97 9:04 AM & 0.87 & 9/11/97 7:21 PM & 0.30 \\
\hline & 3.00 & 10/16/97 12:28 PM & 35.01 & - & - \\
\hline & 8.50 & 10/31/97 12:12 PM & 50.00 & 9/8/97 10:20 AM & $-3.08^{\dagger}$ \\
\hline & 10.10 & 9/25/97 6:12 PM & 14.25 & 9/19/97 5:31 PM & 8.22 \\
\hline \multirow[t]{4}{*}{$\mathrm{I}-2$} & 0.30 & 9/11/97 7:37 PM & 0.31 & 9/10/97 3:13 PM & $-0.88^{\dagger}$ \\
\hline & 1.50 & 9/12/97 3:17 PM & 1.13 & - & - \\
\hline & 3.00 & 9/20/97 12:22 PM & 9.00 & - & - \\
\hline & 6.10 & 9/18/97 7:29 PM & 7.30 & 9/11/97 7:20 PM & 0.30 \\
\hline \multirow[t]{2}{*}{$\mathrm{I}-3$} & 0.30 & 9/11/97 6:59 PM & 0.28 & 9/10/97 3:49 PM & $-0.85^{\dagger}$ \\
\hline & 1.50 & 10/4/97 12:48 PM & 23.02 & 9/8/97 10:40 AM & $-3.07^{\dagger}$ \\
\hline $\mathrm{T}-3$ & 4.60 & 9/26/97 2:34 PM & 15.10 & - & - \\
\hline \multirow[t]{4}{*}{$\mathrm{T}-4$} & 0.60 & 9/21/97 10:00 AM & 9.91 & 9/19/97 4:35 PM & 8.18 \\
\hline & 2.70 & 9/20/97 1:26 PM & 9.05 & - & - \\
\hline & 4.30 & 9/17/97 6:50 PM & 6.27 & - & - \\
\hline & 5.80 & 9/21/97 10:00 AM & 9.91 & 9/20/97 1:23 PM & 9.05 \\
\hline $\mathrm{T}-5$ & 3.00 & 10/16/97 1:41 PM & 35.06 & 10/4/97 12:58 PM & 23.03 \\
\hline \multirow[t]{2}{*}{ T-6 } & 0.60 & 9/11/97 7:10 PM & 0.29 & - & - \\
\hline & 4.60 & 11/3/97 3:30 PM & 53.14 & - & - \\
\hline \multirow[t]{2}{*}{$\mathrm{T}-7$} & 0.60 & 9/11/97 7:04 PM & 0.28 & 9/10/97 3:42 PM & $-0.86^{\dagger}$ \\
\hline & 3.00 & 9/20/97 12:45 PM & 9.02 & - & - \\
\hline T-8 & 0.30 & 9/12/97 8>55 AM & 0.86 & - & - \\
\hline \multirow[t]{2}{*}{ T-9 } & 0.30 & 9/11/97 7:34 PM & 0.30 & 9/10/97 3:27 PM & $-0.87^{\dagger}$ \\
\hline & 1.50 & 9/11/97 7:32 PM & 0.30 & - & - \\
\hline
\end{tabular}

${ }^{\dagger}$ Negative time in minimum Br- arrival time column indicates sample was obtained before time datum (start of 97-1). Time datum for Br- arrival times: 9/11/97 12:15 PM

Table 4: Bromide arrival times during the $97-1$ to $97-4$ infiltration tests. 


\begin{tabular}{|c|c|c|c|c|c|c|c|c|c|c|}
\hline \multirow[t]{3}{*}{ Zone } & \multicolumn{6}{|c|}{ Fracture Properties } & \multicolumn{4}{|c|}{$\begin{array}{l}\text { Matrix Properties } \\
\end{array}$} \\
\hline & \multirow{2}{*}{$\begin{array}{c}\text { Porosity } \\
\text { scaling } \\
\text { factor }\end{array}$} & \multirow{2}{*}{$\begin{array}{c}\text { porosity } \\
(-)\end{array}$} & \multicolumn{3}{|c|}{ van Genuchten } & \multirow{2}{*}{$\begin{array}{c}\text { Corey } \\
A_{f m} \\
(-)\end{array}$} & \multirow{2}{*}{$\begin{array}{c}\text { permeability } \\
\left(\mathrm{m}^{2}\right)\end{array}$} & \multirow[t]{2}{*}{ porosity } & \multicolumn{2}{|c|}{ van Genuchten } \\
\hline & & & $\begin{array}{c}\alpha \\
\left(\mathbf{P a}^{-1}\right)\end{array}$ & $\begin{array}{c}m \\
(-)\end{array}$ & $\begin{array}{c}A_{f m} \\
(-)\end{array}$ & & & & $\begin{array}{c}\alpha \\
\left(\mathbf{P a}^{-1}\right)\end{array}$ & $\begin{array}{l}m \\
(-)\end{array}$ \\
\hline $0.0-0.2$ & 50 & 0.013 & $5 \times 10^{-4}$ & 0.5 & 0.01 & 0.1 & $1.0 \times 10^{-14}$ & 0.2 & $5 \times 10^{-5}$ & 0.25 \\
\hline $0.2-0.4$ & 50 & 0.015 & $5 \times 10^{-4}$ & 0.5 & 0.01 & 0.1 & $1.0 \times 10^{-14}$ & 0.2 & $5 \times 10^{-5}$ & 0.25 \\
\hline $0.4-0.6$ & 50 & 0.014 & $5 \times 10^{-4}$ & 0.5 & 0.01 & 0.1 & $1.0 \times 10^{-14}$ & 0.2 & $5 \times 10^{-5}$ & 0.25 \\
\hline $0.6-0.8$ & 50 & 0.009 & $5 \times 10^{-4}$ & 0.5 & 0.01 & 0.1 & $1.0 \times 10^{-14}$ & 0.2 & $5 \times 10^{-5}$ & 0.25 \\
\hline $0.8-1.0$ & 50 & 0.021 & $5 \times 10^{-4}$ & 0.5 & 0.01 & 0.1 & $1.0 \times 10^{-14}$ & 0.2 & $5 \times 10^{-5}$ & 0.25 \\
\hline Rubble zone & 5 & 0.129 & $5 \times 10^{-4}$ & 0.5 & 0.01 & 0.1 & $1.0 \times 10^{-14}$ & 0.2 & $5 \times 10^{-5}$ & 0.25 \\
\hline Lower basalt & 5 & 0.013 & $5 \times 10^{-4}$ & 0.5 & 0.01 & 0.1 & $1.0 \times 10^{-14}$ & 0.2 & $5 \times 10^{-5}$ & 0.25 \\
\hline
\end{tabular}

Table 5: Fracture and matrix calibration parameters from the analysis of the infiltration test data. 


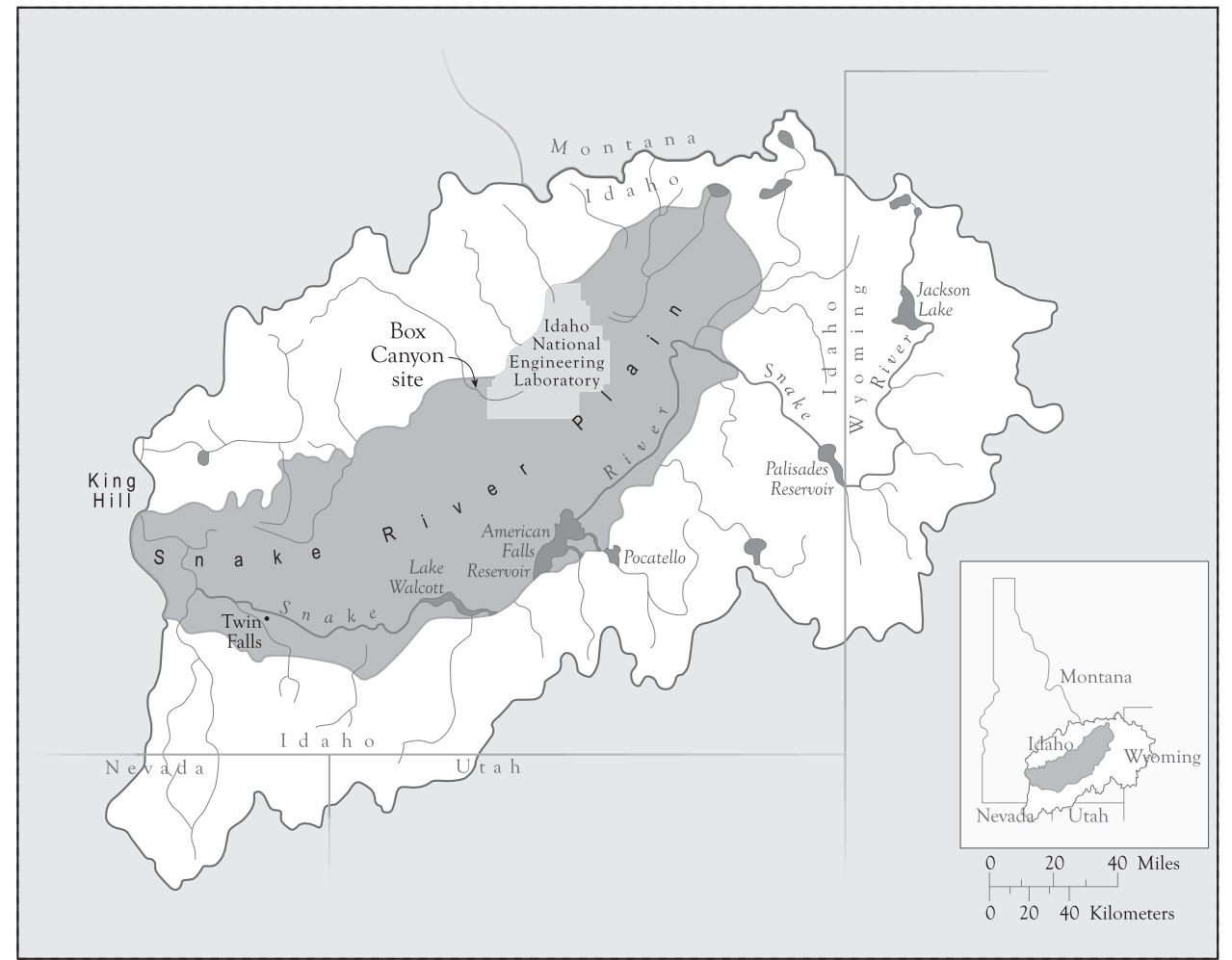

Figure 1: Map of East River Snake River Plain showing the location of the Box Canyon experimental site. 
(a)

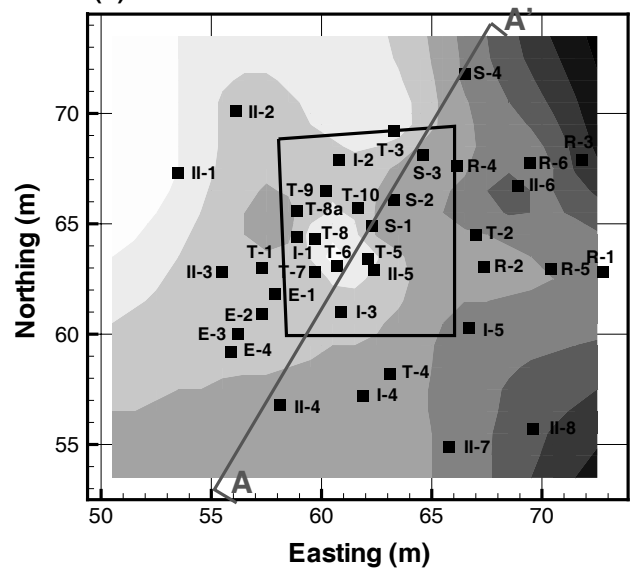

(b)

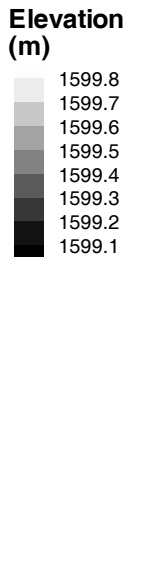

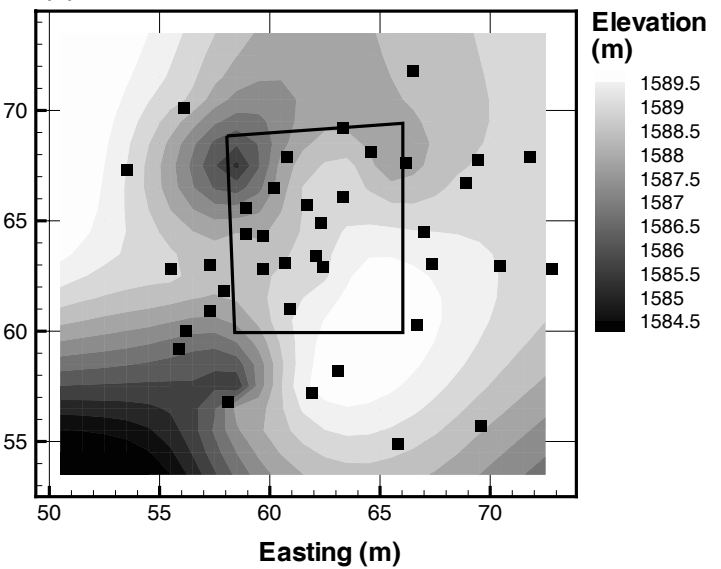

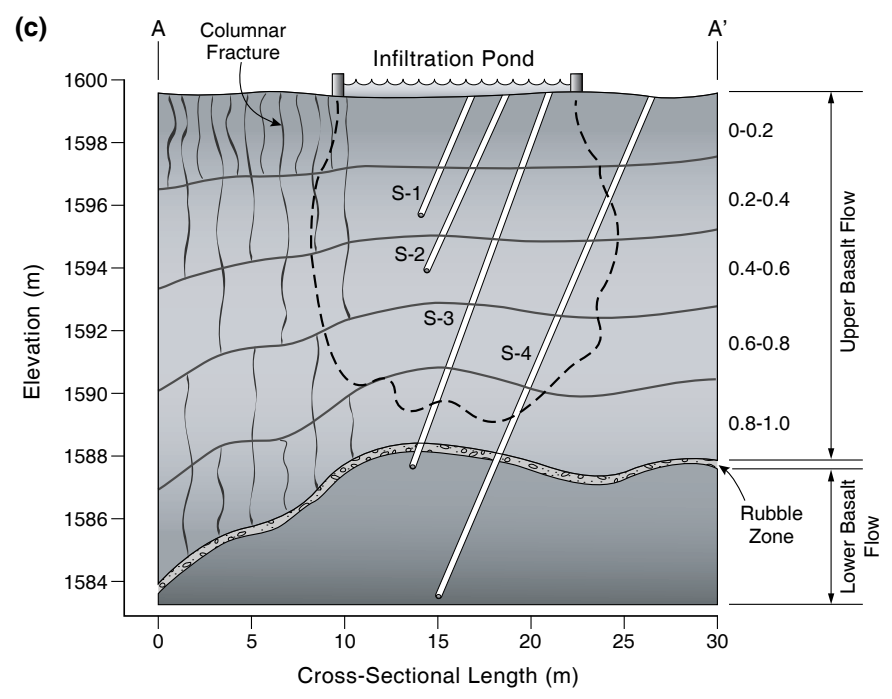

Figure 2: Elevation of (a) ground surface, and (b) top of rubble zone with all well locations and perimeter of the infiltration pond, and (c) cross section through upper basalt flow. The "S" series of wells (S-1 to S-4) consist of slanted boreholes while the "I", "II", "E", "R", "T" series of wells are vertical boreholes. 


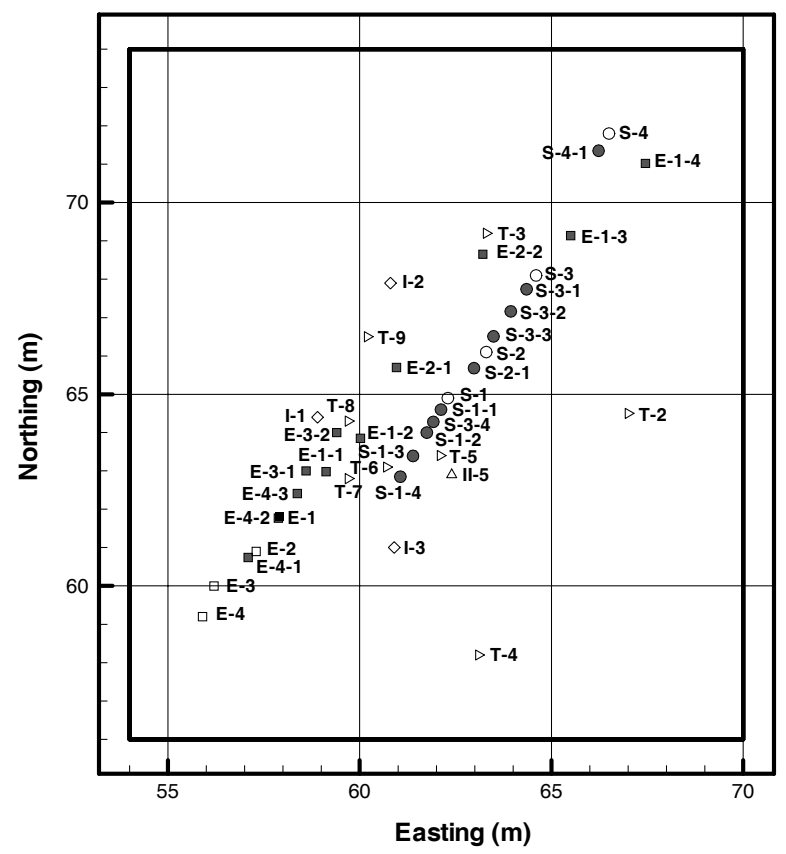

Figure 3: Plan view of the location of borehole intersections with active water conducting fractures. Open symbols indicate the surface location of a borehole while shaded symbols indicate the intersection with active water conducting fractures.

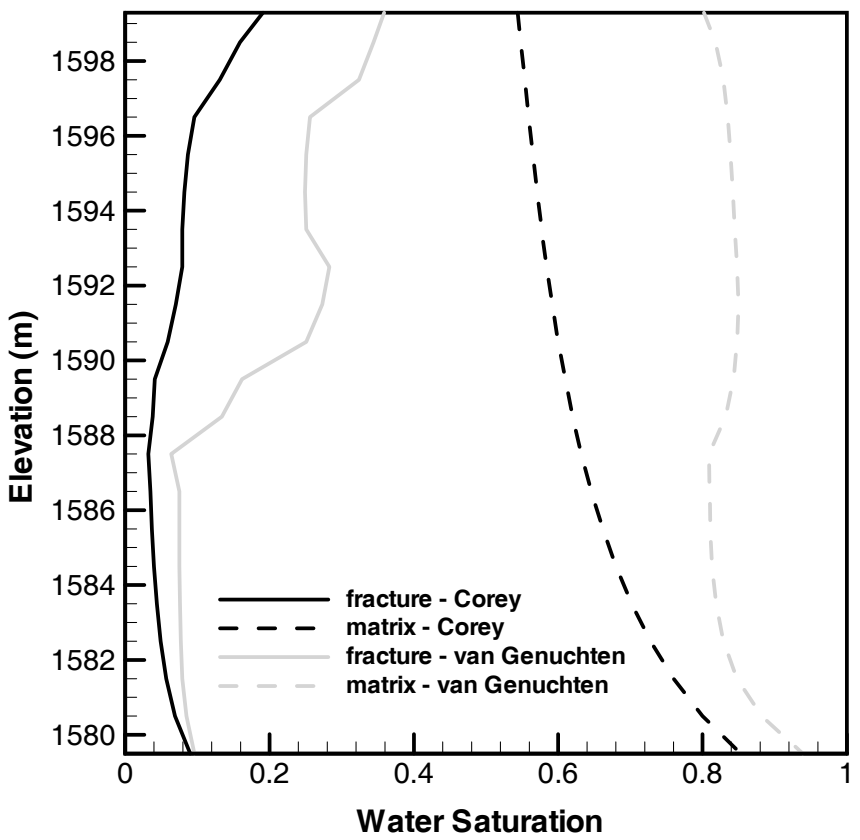

Figure 4: Water saturation profile in borehole I-1 for the fracture and matrix continua immediately prior to the 97-1 infiltration test. 
(a)

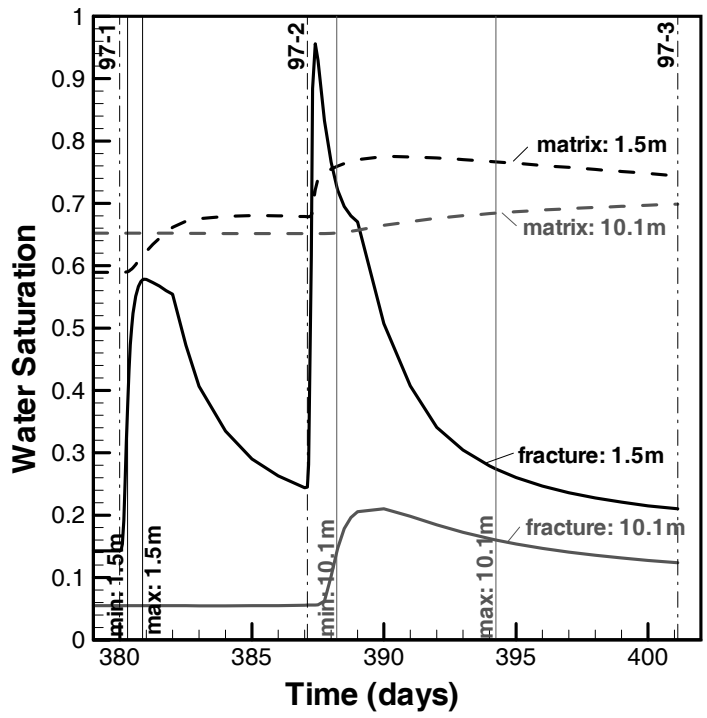

(b)

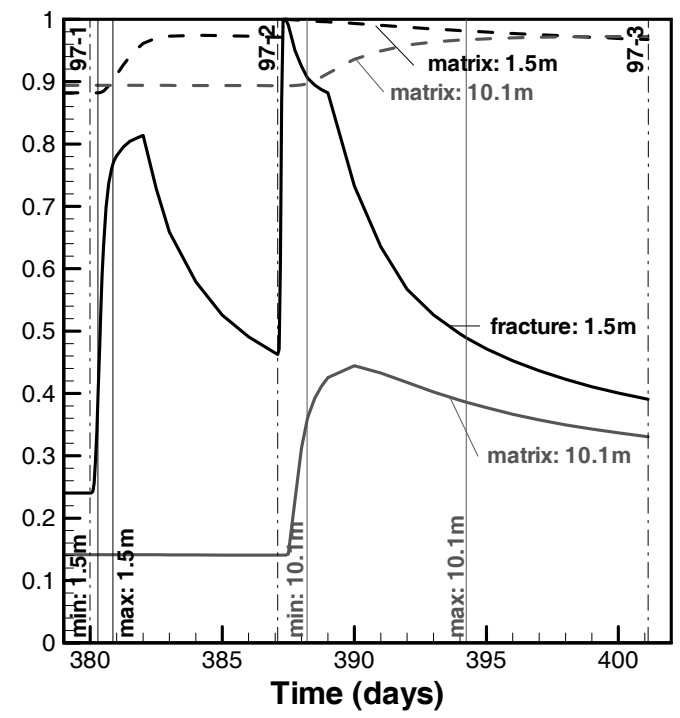

Figure 5: Simulated infiltration front arrival times at sampling points in borehole I-1 given by water saturation in the fracture and matrix continua using (a) Corey and (b) van Genuchten relative permeability functions.

(a)

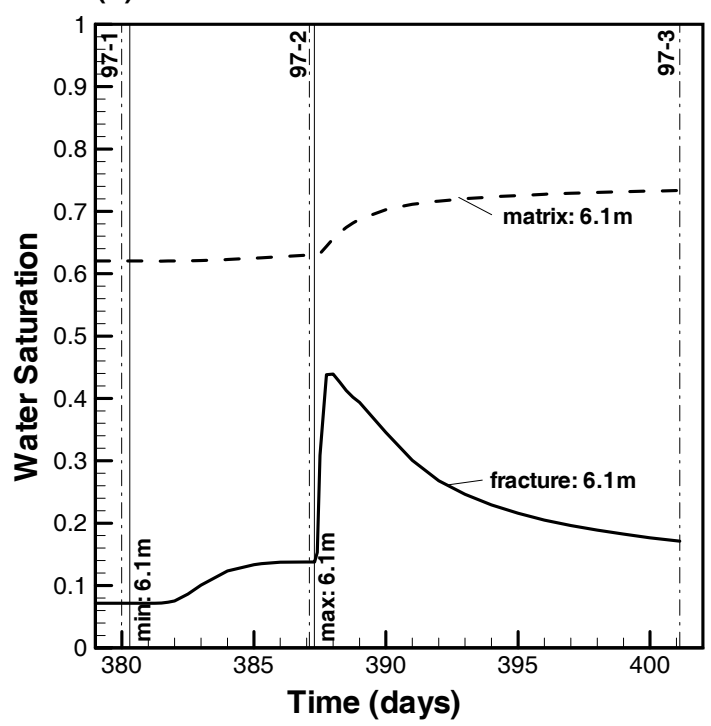

(b)

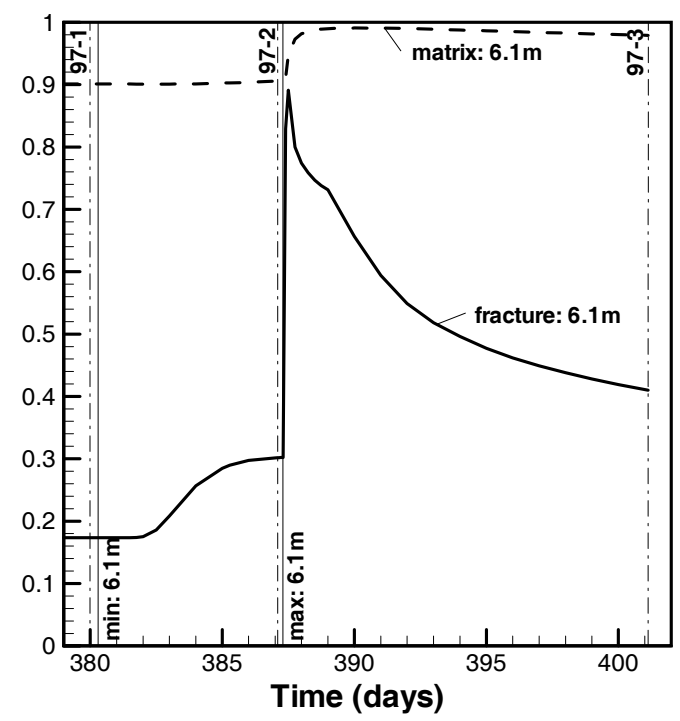

Figure 6: Simulated infiltration front arrival time in borehole I-2 given by water saturation in the fracture and matrix continua using (a) Corey and (b) van Genuchten relative permeability functions. 
(a)

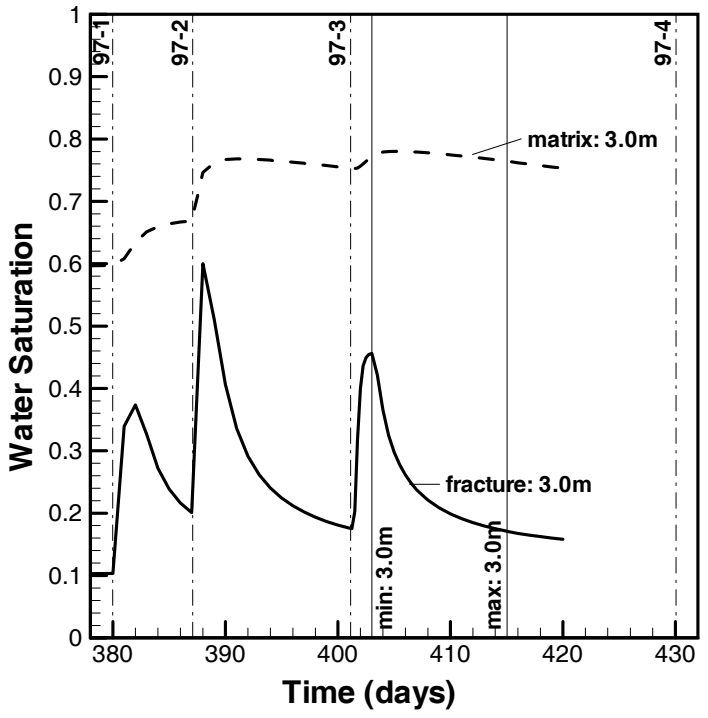

(b)

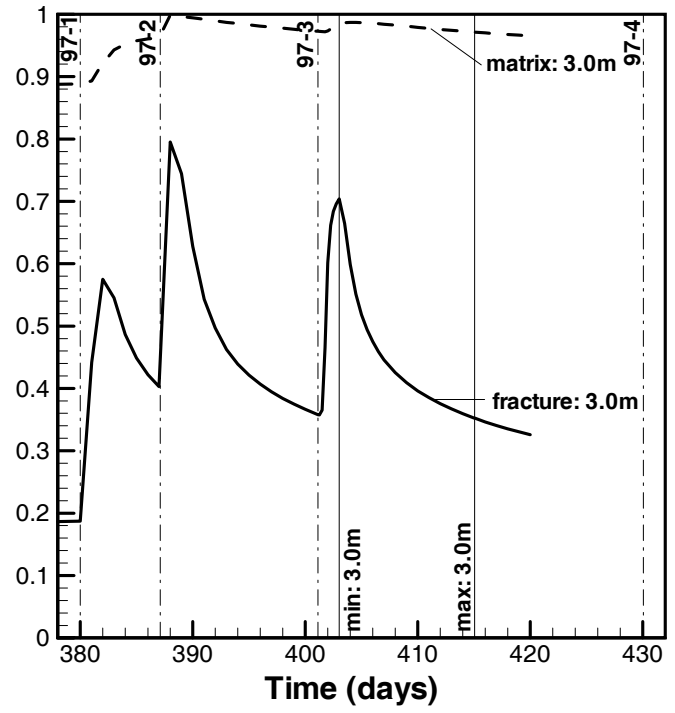

Figure 7: Simulated infiltration front arrival time in borehole T-5 given by water saturation in the fracture and matrix continua using (a) Corey and (b) van Genuchten relative permeability functions. 
(a) $0.0-0.2$

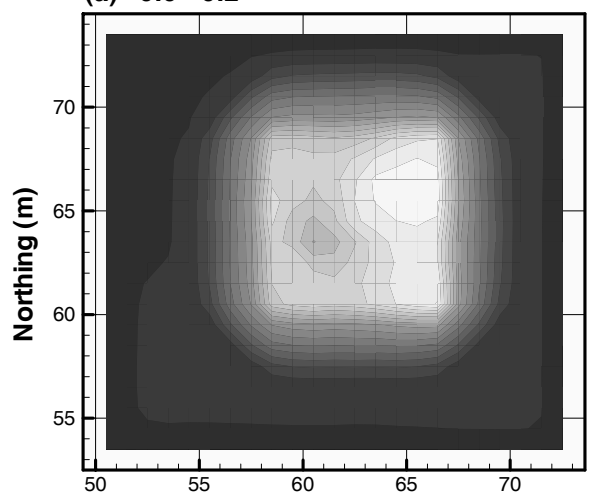

(c) $0.4-0.6$

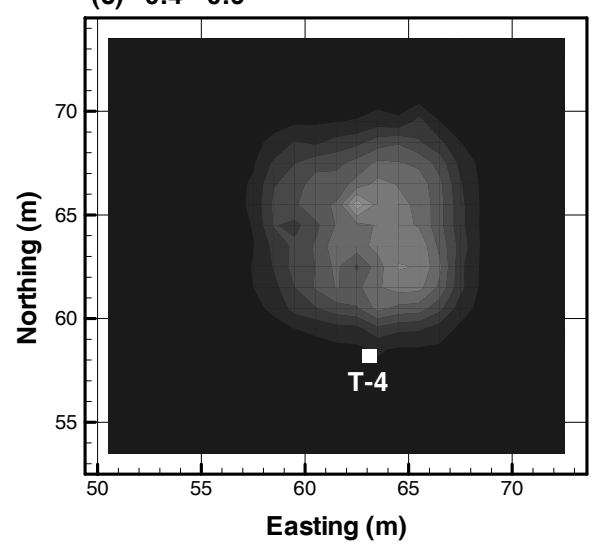

(b) $0.2-0.4$

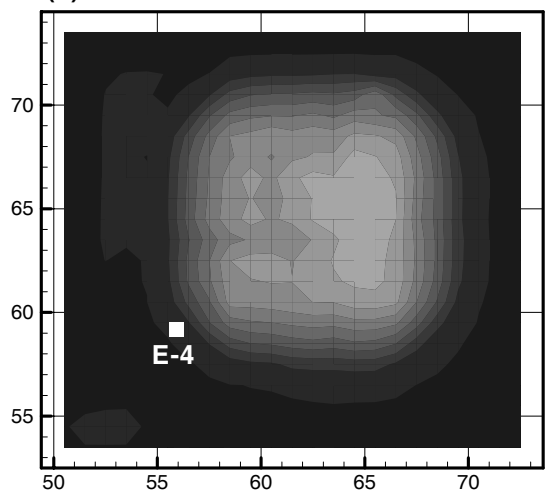

(d) 0.6 - 1.0

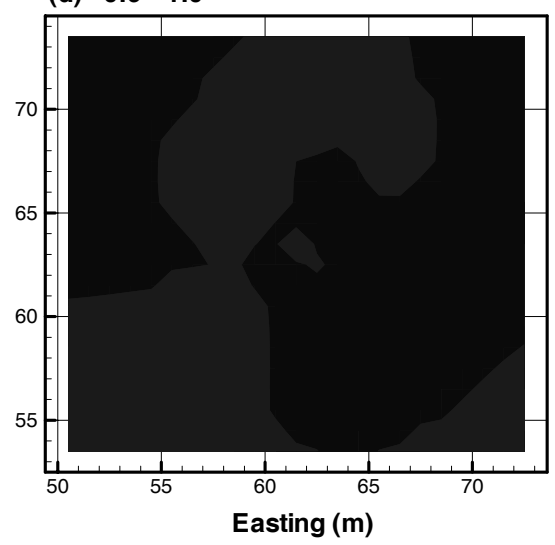

$S_{w}$ fractures

0.8
0.75

0.7
0.65

0.6

0.6
0.55

0.55
0.5

0.5
0.45

0.45
0.4
0.35

0.35

0.3

0.25

0.2
0.15
0.1

0.1
0.05

0.05

Figure 8: Water saturation distribution in the fracture continuum 0.9 days into the $97-2$ infiltration test-388 days since the start of 96-1. 
(a) $0.0-0.2$

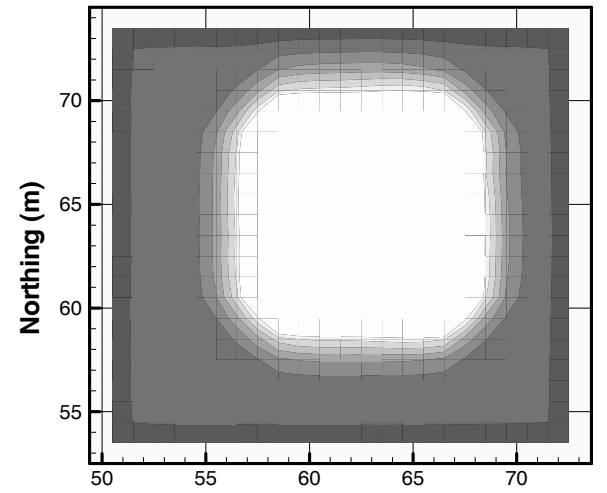

(c) $0.4-0.6$

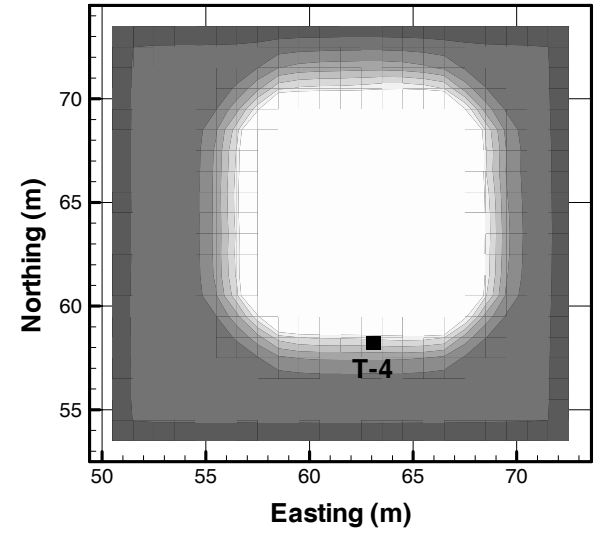

(b) $0.2-0.4$

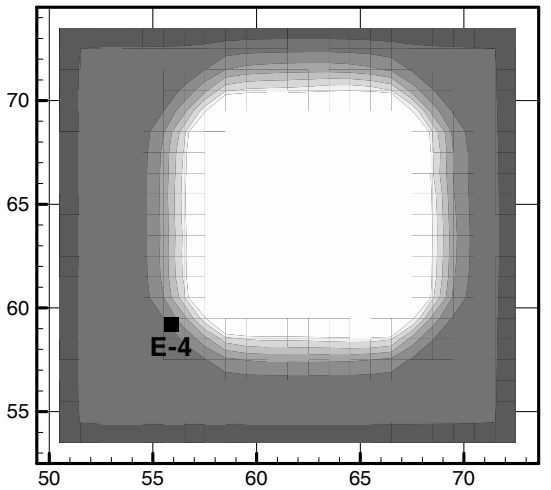

(d) $0.6-1.0$

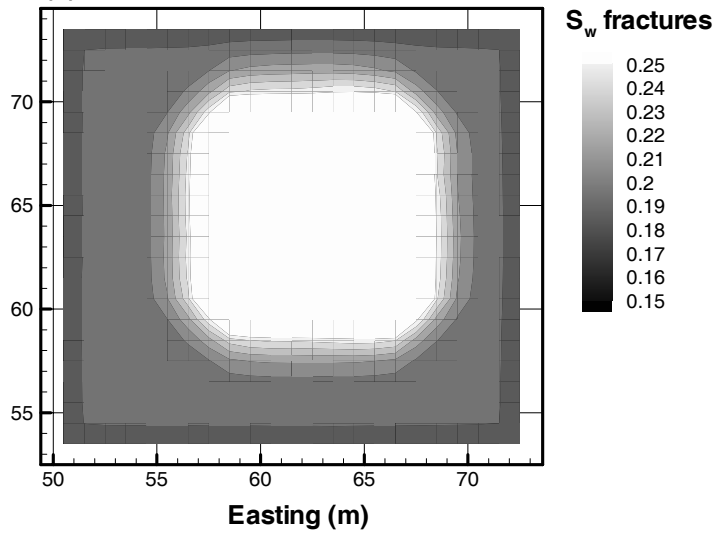

Figure 9: Water saturation distribution in the fracture continuum 2.9 days into the $97-2$ infiltration test -390 days since the start of 96-1. 